\title{
EHMTI-0388. Levels of calcitonin-gene related peptide in medication overuse headache - a pilot study
}

\author{
SB Munksgaard ${ }^{1 *}$, E Frandsen $^{2}$, L Bendtsen ${ }^{1}, \mathrm{RH}$ Jensen $^{1}$ \\ From 4th European Headache and Migraine Trust International Congress: EHMTIC 2014 \\ Copenhagen, Denmark. 18-21 September 2014
}

\section{Background}

Medication-overuse headache $(\mathrm{MOH})$ is a chronic, secondary headache caused by excessive intake of symptomatic medications for an underlying headache, most often tension-type headache or migraine. Previously, elevated calcitonin-gene-related peptide (CGRP) levels were found in migraine patients increasing with migraine frequency and in animal $\mathrm{MOH}$ models.

\section{Aim}

To test whether MOH patients have increased CGRP levels before withdrawal therapy compared with healthy volunteers, and further, if the CGRP level would normalize after withdrawal in parallel with the headache-frequency decrease.

\section{Methods}

Blood samples from $16 \mathrm{MOH}$ patients before and 6 months after withdrawal start and from 30 healthy volunteers of matching sex and age were analyzed. CGRP concentrations were determined by radioimmunoassay using antibody AB4-2905 and $\alpha$-CGRP as calibrator. Free and antibody-bound tracer were separated by Sac-Cel separation. The analyses were done blinded to subject group.

\section{Results}

Median CGRP concentration was $44.4 \mathrm{pmol} / \mathrm{L}$ in $\mathrm{MOH}$ patients before withdrawal and $43.8 \mathrm{pmol} / \mathrm{L}$ in healthy volunteers $(\mathrm{p}=0.72)$. After withdrawal, median CGRPconcentration reduction was $2.1 \%(\mathrm{p}=0.76)$. Median headache-frequency reduction was $42.5 \%$; from 25 days/ month to 12 days/month. Female patients tended to have higher CGRP levels than male patients; 50.6 vs $39.6 \mathrm{pmol} /$ $\mathrm{L}(\mathrm{p}=0.38)$. We were not able to detect any differences in CGRP concentration according to type of drug overused, in relation to underlying headache type, or to reduction in headache frequency.

\section{Conclusions}

No change in CGRP was detected despite dramatic reduction in headache frequency after detoxification of $\mathrm{MOH}$ patients. Thus, our results do not support the notion that CGRP is involved in $\mathrm{MOH}$.

No conflict of interest.

\section{Authors' details}

'Danish Headache Center Department of Neurology, Glostrup Hospital University of Copenhagen, Glostrup, Denmark. ${ }^{2}$ Department of Diagnostics Clinical Physiology and Nuclear Medicine, Glostrup Hospital, Glostrup, Denmark.

Published: 18 September 2014

doi:10.1186/1129-2377-15-S1-19

Cite this article as: Munksgaard et al:: EHMTI-0388. Levels of calcitoningene related peptide in medication overuse headache - a pilot study. The Journal of Headache and Pain 2014 15(Suppl 1):19. 